\title{
BREAKING STRENGTH AND GREEP EXPANSION OF DEPOSITED SNOW
}

\author{
By Z. Watanabe \\ (Department of Physics, Fukushima University, Fukushima City, Japan)
}

\begin{abstract}
The breaking strengths of snow were measured by a new tester which had been made by the author, and were expressed as functions of density or hardness. One special merit of the apparatus is that they are useable even for new snow, and the strengths were easily measured to several grammes per $\mathrm{cm}^{2}$. The creep expansion of snow was measured by using an optical level, and was expressed as a function of snow density, temperature, internal stress, and lapsed time. One point of the measurement is that the creep expansion rate did not become constant, but was decreasing with time even several hours from the beginning of the test.
\end{abstract}

\section{DIMENSIONAL CHANGES OF ICE Ih WITH TIME}

\author{
By PAUL R. CAMP \\ (Department of Physics and Astronomy, University of Maine at Orono, Orono, Maine 04473, \\ U.S.A.)
}

Abstract. Two different types of experiment were reported. Both used a pure single crystal of ice freshly grown in the laboratory at $2 \mathrm{~mm}$ per hour.

Direct volumetric measurements were made by submerging an ice crystal (volume $143 \mathrm{~cm}^{3}$ ) in mercury in a sealed steel container and electronically monitoring the height of the mercury in a manometer tube connected to it. Measurements over a 6 o d period at $-4.0^{\circ} \mathrm{C}$ showed a small gradual decrease in apparent volume. This could be due to the adsorption of perhaps $\mathrm{IO}^{-2} \mathrm{~cm}^{3}$ of air trapped by the mercury at the surface of the ice. The total uncertainties of the experiment are such that we believe we would have observed a volume dilation of as little as $2.5 \times 10^{-6}$ per day.

Direct measurements were also made of the change in length of ice samples from the same crystal. One was cut with length parallel to $c$ and the other perpendicular to $c$. Over a $28 \mathrm{~d}$ period, the fractional change in length at $-\mathrm{I} 3.7^{\circ} \mathrm{C}$ was less than $2 \times 1 \mathrm{IO}^{-7}$ per day $\perp c$ and less than $7 \times \mathrm{IO}^{-8}$ per day $\| c$, leading to an upper bound on volume change of $7 \times \mathrm{IO}^{-7}$ per day.

We conclude that if dilation of ice occurs with time, it is less than $10^{-6}$ per day and therefore probably not a factor which needs consideration in ordinary experiments. 